\title{
Verbal Fluency in Mild Alzheimer's Disease: Transcranial Direct Current Stimulation over the Dorsolateral Prefrontal Cortex
}

\author{
Daniela Smirni $^{\mathrm{a}, \mathrm{b}, *}$, Massimiliano Oliveri ${ }^{\mathrm{a}, \mathrm{b}}$, Eliana Misuraca $^{\mathrm{b}}$, Angela Catania ${ }^{\mathrm{b}}$, \\ Laura Vernuccio $^{\mathrm{c}}$, Valentina Picciolo ${ }^{\mathrm{c}}$, Flora Inzerillo ${ }^{\mathrm{c}}$, Mario Barbagalloc, \\ Lisa Cipolotti ${ }^{\mathrm{d}}$ and Patrizia Turriziani ${ }^{\mathrm{a}, \mathrm{b}}$ \\ ${ }^{a}$ Department of Psychology, Educational Science and Human Movement, University of Palermo, Palermo, Italy \\ ${ }^{\mathrm{b}}$ NeuroTeam Life and Science, Palermo, Italy \\ ${ }^{\mathrm{c}}$ Geriatric Unit, Department of Internal Medicine and Geriatrics, University of Palermo, Palermo, Italy \\ ${ }^{\mathrm{d}}$ Department of Neuropsychology, National Hospital for Neurology and Neurosurgery, London, UK
}

Accepted 22 March 2021

Pre-press 29 April 2021

\begin{abstract}
.
Background: Recent studies showed that in healthy controls and in aphasic patients, inhibitory trains of repetitive transcranial magnetic stimulation (rTMS) over the right prefrontal cortex can improve phonemic fluency performance, while anodal transcranial direct current stimulation (tDCS) over the left prefrontal cortex can improve performance in naming and semantic fluency tasks.

Objective: This study aimed at investigating the effects of cathodal tDCS over the left or the right dorsolateral prefrontal cortex (DLPFC) on verbal fluency tasks (VFT) in patients with mild Alzheimer's disease (AD).

Methods: Forty mild AD patients participated in the study (mean age $73.17 \pm 5.61$ years). All participants underwent cognitive baseline tasks and a VFT twice. Twenty patients randomly received cathodal tDCS to the left or the right DLPFC, and twenty patients were assigned to a control group in which only the two measures of VFT were taken, without the administration of the tDCS.

Results: A significant improvement of performance on the VFT in AD patients was present after tDCS over the right DLPFC $(p=0.001)$. Instead, no difference was detected between the two VFTs sessions after tDCS over the left DLPFC $(p=0.42)$. Furthermore, these results cannot be related to task learning effects, since no significant difference was found between the two VFT sessions in the control group $(p=0.73)$.

Conclusion: These data suggest that tDCS over DLPFC can improve VFT performance in AD patients. A hypothesis is that tDCS enhances adaptive patterns of brain activity between functionally connected areas.
\end{abstract}

Keywords: Dorsolateral prefrontal cortex, mild Alzheimer's disease, transcranial direct current stimulation, verbal fluency

*Correspondence to: Daniela Smirni, viale delle Scienze, Ed.15, 90128, Palermo, Italy. Tel.: +39 0 9123897748; E-mail: daniela.smirni@unipa.it.; ORCID ID 0000-0002-4410-2047

\section{INTRODUCTION}

Non-invasive brain stimulation (NIBS) is a stimulation technique that can be used to modulate spontaneous cortical activity in the human brain. The two most commonly used techniques of NIBS are transcranial magnetic stimulation (TMS) and transcranial 
direct current stimulation (tDCS). In the TMS, a rapidly changing current within a conducting coil is used to induce a strong, but relatively focal, magnetic field. When the coil is placed on the scalp, the magnetic field induces a physiological response (i.e., depolarization and/or spiking) in the underlying neural tissue [1-3]. Different stimulation frequencies can enhance or inhibit cortical excitability in the target cortical region $[4,5]$. Unlike TMS, tDCS delivers weak polarizing continuous direct currents $(0.5-2.0 \mathrm{~mA})$ to the cortex via two electrodes placed on the scalp, to modulate neuronal transmembrane potential toward hyperpolarization or depolarization, thereby altering plasticity in the stimulated brain regions $[6,7]$. Although they are different in some respects, both tools can induce long-term after effects on cortical excitability and neuroplasticity.

NIBS is being increasingly used to study the connection between language processes and the underlying brain networks [8-15]. Just as an example, recent studies have reported that in healthy subjects inhibitory repetitive TMS (rTMS) over the right lateral frontal cortex significantly improves phonemic fluency performance [16], while excitatory tDCS over the left inferior frontal gyrus improves performance in naming, phonemic, and semantic fluency tasks [17-20].

The studies that investigated language functioning, for the most part, used language fluency tasks or naming tasks. Picture naming involves producing a noun or verb for a visually presented target and it is the most direct measure of language production performance. During this task, a large left frontotemporal network is activated, extending from the internal frontal regions to the upper temporal and lower parietal posterior regions [21, 22]. Verbal fluency tasks require the subject to produce as many words as possible from a given semantic category (semantic fluency) or starting with a given letter (phonemic fluency) within a time constraint. During these tasks, left frontal, temporal, and parietal areas become activated, with separated activity of the middle temporal gyrus in the semantic and of the inferior frontal gyrus in the phonemic fluency task [23-25]. Verbal fluency tasks are believed to require both language processes, such as lexical retrieval and semantic memory [26-30], and executive functions, such as the voluntary production of words and the ability to inhibit inappropriate responses (interferent words, that do not match the criteria) [31-37].

Many studies have reported that rTMS and tDCS can modulate the language system in aphasic populations [38]. The rTMS allows painless, noninvasive stimulation of the human cortex from outside the skull. It uses magnetic fields to create electrical currents in cortical regions of interest and produces changes in cortical excitability [39]. When delivered to the same cortical region, slow $(1 \mathrm{~Hz})$ rTMS appears to decrease excitability in the targeted cortical area that lasts beyond the duration of the train itself [40], leading to measurable behavioral effects. Conversely, rapid rTMS $(>5 \mathrm{~Hz})$ increases cortical excitability [41].

Several rTMS studies with aphasic patients have observed high activation, during language tasks, in parts of right cortex homologous to the Broca's area, which may be maladaptive $[42,43]$. When applied to the homologous areas in the undamaged hemisphere, low-frequency $(1 \mathrm{~Hz})$ rTMS may suppress the inhibitory process of that regions, permitting reactivation of some areas within the damaged hemisphere and promoting some functional recovery [39]. Evidence comes from patient studies showing significant improvement in verbal fluency [44], more accurate and faster naming [43] and picture naming [45], following $1 \mathrm{~Hz}$ inhibitory rTMS sessions on the cortex right homologous to Broca's area.

Similarly, tDCS also proved to be a non-invasive, safe, and painless method for modulating language functions in aphasic patients [12]. The tDCS delivers a weak polarizing electric current to the cortex through a pair of electrodes, and, depending on the polarity of the current flow, brain excitability can be either increased by anodal stimulation (A-tDCS) or decreased by cathodal stimulation (C-tDCS) [46]. Some studies have shown that the A-tDCS over the left frontal cortex [47-49] and the left posterior cortex $[50,51]$ can lead to greater naming accuracy in stroke patients with aphasia. The A-tDCS was applied also over the non-language dominant hemisphere (right temporo-parietal cortex) and the study showed that stimulation further improved language training outcome [52]. Instead, Kang and colleagues applied C-tDCS on the Broca's homologue area, and the authors concluded that C-tDCS over the right Broca's homologue area improves naming accuracy [53].

The performance on verbal fluency tasks in patients with Alzheimer's disease (AD) or mild cognitive impairment (MCI) has been extensively investigated [54-56]. Many studies have also proposed verbal fluency tasks as a diagnostic tool to differentiate subjects with normal cognitive functioning from patients with mild AD [57-62]. 
However, although numerous studies applied brain stimulation in $\mathrm{AD}$, the majority of these studies focused on memory [63-71], while the modulation of linguistic functions in AD remains poorly investigated.

Cotelli and colleagues [72] reported significant effects on auditory sentence comprehension of AD patients of $20 \mathrm{~Hz}$ rTMS trains over the left dorsolateral prefrontal cortex. The same authors had also observed that high frequency rTMS applied to the left and right DLPFC during object and action naming in $\mathrm{AD}$ patients improved performance also in advanced stages of dementia [73]. In this case, the rTMS effect in normal controls was limited to the left-sided stimulation, whereas the improvement was bilateral in AD patients, with both mild and severe disease stage. The authors explained this finding with the recruitment of the right hemispheric resources to support poor naming performance, like a compensatory process. Another recent study reported an improvement in auditory comprehension task after A-tDCS over the right posterior cortex (Brodmann areas 39/40) in a neurodegenerative patient [74].

The current study aimed to investigate the effects of C-tDCS over the left or right DLPFC on verbal fluency tasks in patients with mild AD. Based on the evidence that emerged in previous studies that investigated fluence through right inhibitory rTMS in healthy subjects, C-tDCS was assumed could be based on the same assumptions.

The underlying hypothesis was that right $\mathrm{C}$-tDCS could improve phonemic fluency tasks by modulating transcallosal connections between the left and right hemisphere. The same evidence was observed in healthy subjects [16] and in memory functions, with MCI and AD patients [63, 75] applying inhibitory rTMS. The hypothesis is to extend the same observations of memory into language-related functions.

\section{MATERIALS AND METHODS}

\section{Participants}

Participants were recruited among the patients of the Geriatric Unit, Department of Internal Medicine and Geriatrics, University of Palermo. Patients underwent a comprehensive diagnostic investigation, which included anamnestic and clinical collection, a neurological and neuropsychiatric examination, brain MRI, and an extensive neuropsychological assessment to explore all cognitive domains.
Inclusion criteria were: mild AD diagnosis, no history of other neurological or psychiatric disorders, no signs of concomitant cerebrovascular disease, no alcohol abuse, psychosis, or major depression.

The diagnosis of mild AD was obtained according to the diagnostic criteria for prodromal AD [76] referring to the early symptomatic phase of $\mathrm{AD}$, characterized by episodic memory loss in the presence of AD pathology. Patients who met the inclusion and diagnostic criteria were called for recruitment in a second meeting within one week.

The sample consisted of 40 patients, 13 males (32.5\%) and 27 females (67.5\%), with mean age of $73.17 \pm 5.61$ years (age range 62-80), mean education of $12.7 \pm 3.58$ years (education range $8-18$ ).

All patients were free of medications. Written informed consent was obtained from all patients in accordance with the independent local Ethics Committee. Participating patients could freely drop out of the study at any time due to fatigue, discomfort, or poor tolerance to tDCS administration.

\section{METHODS}

Patients underwent an extensive neuropsychological assessment exploring all cognitive domains: general cognitive level, non-verbal intellective abilities, verbal and non-verbal short-term memory, visual recognition memory, verbal memory, naming, interference inhibition, apraxia. In addition, functional and psychological domains were studied, such as the level of anxiety and depression and the simple and complex autonomies of daily living.

Participants were randomly assigned to two independent groups: experimental and control. In the experimental group (n. 20: 6 males, 14 females) the participants were administered the cognitive baseline tasks, cathodal tDCS and the phonemic fluency tasks (VFTs). The VFTs were given twice, before and immediately after tDCS stimulation. The experimental group was divided into two paired groups of 10 patients: one group received cathodal tDCS to the right DLPFC and the other group received cathodal tDCS to the left DLPFC. In the control group (n. 20: 7 males, 13 females) the participants were administered the cognitive baseline tasks and the phonemic fluency tasks, to evaluate the potential contribution of learning effects on VFTs. The patients were informed about the assigned group to know their availability to receive brain stimulation. 


\section{Neuropsychological and functional examination}

All participants received a comprehensive neuropsychological examination including measures of general cognition, attention, naming, memory, working memory, executive functions, and psychological factors such as anxiety and depression. The following cognitive tests were administered: 1) The MiniMental State Examination (MMSE) [77], assessing the level of cognitive impairment in elderly or presumed dementia; 2) The Raven's Coloured Progressive Matrices (RCPM) [78, 79], assessing nonverbal intellective abilities, attentional processes and abstract reasoning in adults. The test requires to choose among six options the missing element in a drawing. One point was given for each correct answer and the total score was the sum of the correct answers with a maximum score of 36; 3) The Digit Span forward and backward [80], evaluating short-term verbal memory. The task consists of repeating a series of numbers of progressively increasing length both forward and backward. The verbal span score was calculated from the longest sequence of digits that was repeated after a single presentation; 4) The Corsi Span forward and backward [80], assessing visuo-spatial short-term memory. The task involves reproducing series of visuospatial sequences of increasing length both forward and backward. The visuospatial memory span score was calculated based on the length of the longest correctly reproduced sequence; 5) The Italian version of the Recognition Memory Test for Faces (RMT-Faces) [81, 82], assessing visual recognition memory. The total score is the number of correctly items recognized; 6) The Auditory-Verbal Learning Test (AVLT) $[83,84]$ assessing verbal memory. The number of words correctly recalled in the five immediate trials gives the total immediate recall score, and the number of words correctly recalled in the 15 min delayed trial gives the delayed recall score; 7) Two tasks of the Battery for the Aphasic Deficit Analysis (BADA) [85], assessing the ability of naming nouns and verbs. The number of correctly named items is the test score; 8) The short version of Stroop Color-Word Test, assessing the ability to inhibit interference, that is part of executive functions [86]. The test evaluates how many of the 30 words have been correctly reported with the color they are printed and the time taken; 9) Copying drawings without and with programming elements (CD, CDP) [83, 87] consisting in the freehand copy (CD- without programming elements) or with programming elements (CDP-points, lines to be completed with segments) of three drawings. The scoring consists in the evaluation of the graphic lines copied correctly with a maximum score of 12 for CD and 70 for CDP. 10) Hospital Anxiety and Depression Scale (HADS) [88] a self-rating questionnaire to evaluate the presence and severity of anxiety and depression. The questionnaire provides two separate indices, one for anxiety scale and one for depression scale. A score greater than 8 on each subscale indicates the presence of mild anxiety or depression, a score above 10 indicates a pathological condition of anxiety or depression; 11) Activities of Daily Living (ADL) [89], assessing self-maintenance and Instrumental Activities of Daily Living (IADL) [90], assessing instrumental activities of daily living.

\section{Transcranial direct current stimulation}

The C-tDCS was applied using a battery-driven BrainStim stimulator (EMS, Italy), with a pair of surface-soaked sponge electrodes $(5 \mathrm{~cm} \times 7 \mathrm{~cm})$. A constant current of $1 \mathrm{~mA}$ intensity was delivered for $20 \mathrm{~min}$ positioning the cathode over the left or right DLPFC (F3/F4 sites according to extended International 10-20 System for EEG electrode placement) and the anode above the contralateral shoulder [47, 91]. Based on the existing literature, such electrode positioning was chosen to avoid potential confounding factors resulting from the placement of two polarity electrodes close to the brain (as it is difficult to deduce which electrode is affecting performance) $[49,92]$.

The tDCS was applied in the interval between the two phonemic fluency testing sessions.

Furthermore, tDCS has been applied according to safety guidelines, to allow safe brain stimulation with minor side effects [93-95]. Subjective perceptions of fatigue, discomfort and pain were assessed during the administration of tDCS.

\section{Phonemic fluency tasks}

Two phonemic fluency tasks, standardized for the Italian population, were used [83, 87, 96, 97]. Both tasks require participants to generate as many words as possible starting with a given letter within $1 \mathrm{~min}$, excluding proper nouns and words differing only for the suffix. In one of the two phonemic fluency tasks, the 3 letters used were ' $F$ ' ' $A$ ' ' $S$ '. In the second task, the 3 letters used were ' $F$ ' ' $P$ ' ' $L$ '. The two versions of the task were used, in a balanced manner, the same number of times before and after the C-tDCS administration. From now on, the task used 
before stimulation will be identified as 'pre' and the one used after stimulation as 'post'.

\section{Statistical analyses}

The experimental group and the control group were compared for demographic characteristics (age, education, and sex) using the independent $t$-test and the chi-square test.

ANOVA for repeated measures was used to compare the mean number of words produced in the two sessions of phonemic fluency tasks (pre and post) by the 3 groups (left DLPFC, right DLPFC and controls).

An additional one-way ANOVA for repeated measures was computed to compare VFTs performance between the two experimental groups to analyze the effect of the stimulation site. The between-subjects factor was Side (left versus right DLPFC). The within-subjects factor was Session (pre versus post). Planned comparisons, using the Scheffè test, were carried out if overall tests were significant. Effect size was calculated on the differences between pre- and post-task in the left DLPFC, right DLPFC and control groups using Cohen's d. Furthermore, one-way repeated measures ANOVA was computed to compare the two sessions of VFTs (pre versus post) in the control group, to evaluate the potential contribution of learning effects.

A $p$ value $<0.05$ was set as indication of statistical significance for all analyses.

\section{RESULTS}

No patient dropped out of the study because they reported discomfort or pain during tDCS administration. The only effect reported concerns a minimal somatosensory. Some subjects reported feeling current electricity as an itchy sensation under both electrodes during the early rising phase of the direct current, that is, during the first few seconds of stimulation [93-95].

The two groups, experimental versus controls, can be considered overlapping both for demographic characteristics and for neuropsychological and functional examination.

No differences in age [ $t$-test $\left.{ }_{(38)}=0.25 ; p=0.80\right]$, education $\left[t\right.$-test $\left.{ }_{(38)}=0.09 ; p=0.93\right]$, and sex distribution $\left[\chi_{(1, n=40)}^{2}=0.11 ; p=0.74\right]$ were found between the two groups (Table 1). Similarly, the cognitive domains investigated were completely overlapping among the two groups and no comparison
Table 1

Demographic characteristics and cognitive results of the sample

\begin{tabular}{lcc}
\hline & $\begin{array}{c}\text { Experimental } \\
\text { group } \\
\text { (mean } \pm \text { S.D.) }\end{array}$ & $\begin{array}{c}\text { Control } \\
\text { group } \\
\text { (mean } \pm \text { S.D.) }\end{array}$ \\
\hline Age (y) & $73.4 \pm 5.67$ & $72.95 \pm 5.55$ \\
Years of Education & $12.75 \pm 3.43$ & $12.65 \pm 3.72$ \\
MMSE & $22.45 \pm 2.12$ & $22.8 \pm 2.42$ \\
RCPM & $22.95 \pm 4.92$ & $23.35 \pm 5.24$ \\
Digit Span (forward) & $4.75 \pm 0.85$ & $4.8 \pm 0.89$ \\
Digit Span (backward) & $3.35 \pm 0.81$ & $3.4 \pm 0.88$ \\
Corsi Span (forward) & $4.2 \pm 0.76$ & $4.3 \pm 0.80$ \\
Corsi Span (backward) & $3.2 \pm 0.69$ & $3.3 \pm 0.74$ \\
RMT (Faces) & $17.8 \pm 4.46$ & $18.4 \pm 4.49$ \\
AVLT immediate recall & $24.4 \pm 7.8$ & $25.4 \pm 7$ \\
AVLT delayed recall & $3.95 \pm 2.52$ & $3.8 \pm 2.69$ \\
BADA (nouns) & $25.1 \pm 3.49$ & $25.9 \pm 3.06$ \\
BADA (verbs) & $21.3 \pm 4.34$ & $22.7 \pm 3.35$ \\
Stroop (Time) & $76.3 \pm 32.67$ & $74.25 \pm 31.82$ \\
Stroop (errors) & $2.45 \pm 2.52$ & $2.55 \pm 2.89$ \\
CD & $8.8 \pm 1.91$ & $8.75 \pm 1.86$ \\
CDP & $66.15 \pm 5.01$ & $67 \pm 4.58$ \\
HADS Anxiety & $5.63 \pm 2.24$ & $5.85 \pm 2.6$ \\
HADS Depression & $3.68 \pm 2.06$ & $3.6 \pm 2.09$ \\
ADL & $5.85 \pm 0.37$ & $5.8 \pm 0.41$ \\
IADL & $7.15 \pm 1.14$ & $7.3 \pm 1.13$ \\
\hline
\end{tabular}

F-test and $p$-value did not reach statistically significant levels in any test. MMSE, Mini-Mental State Examination; RCPM, Raven's Coloured Progressive Matrices; RMT, Recognition Memory Test; AVLT, Auditory-Verbal Learning Test; BADA, Battery for the Aphasic Deficit Analysis; CD, copying drawings; CDP, copying drawings with programming elements; HADS, Hospital Anxiety and Depression Scale; ADL, Activities of Daily Living; IADL, Instrumental Activities of Daily Living.

between the means of the cognitive tests administered was statistically significant (Table 1).

Comparing the mean number of words produced in the two testing sessions (pre and post) by the 3 groups (left DLPFC, right DLPFC and controls), ANOVA showed no differences between the means of the three groups in the pre session $\left[\mathrm{F}_{(2,37)}=0.19 ; p=0.824\right]$. Instead, significant differences emerged in the post session $\left[\mathrm{F}_{(2,37)}=10.82 ; p=0.001\right]$ (Table 2). Posthoc tests revealed no significant difference between the phonemic fluency performance of the control and the left DLPFC group $(p=0.674)$. Conversely, there were significant differences between the VFT of the left DLPFC and the right DLPFC group $(p<0.001)$, and between the right DLPFC group and the controls $(p<0.001)$ (Table 2).

Next, the effects of inhibitory tDCS over DLPFCs in the fluency tasks were evaluated. When the pre phonemic fluency testing session and the post phonemic fluency testing session after stimulation on the left DLPFC were compared, there was no significant change in performance $\left[\mathrm{F}_{(1,18)}=0.697\right.$, 
Table 2

Phonemic Fluency performance of the experimental (left and right DLPFC) and control groups: mean number of words and standard deviations, ANOVA and post-hoc tests

\begin{tabular}{|c|c|c|c|c|c|c|c|c|}
\hline \multirow[t]{2}{*}{ Session } & \multirow{2}{*}{$\begin{array}{c}\text { L-DLPFC } \\
(\text { mean } \pm \text { S.D. })\end{array}$} & \multirow{2}{*}{$\begin{array}{c}\text { R-DLPFC } \\
(\text { mean } \pm \text { S.D. })\end{array}$} & \multirow{2}{*}{$\begin{array}{c}\text { Controls } \\
(\text { mean } \pm \text { S.D. })\end{array}$} & \multirow{2}{*}{$\begin{array}{c}\text { F-test } \\
\text { (d.f.=2,37) }\end{array}$} & \multirow[t]{2}{*}{$p$} & \multicolumn{3}{|c|}{ Post-hoc Test } \\
\hline & & & & & & $\begin{array}{l}\text { L-DLPFC versus } \\
\text { R-DLPFC }\end{array}$ & $\begin{array}{c}\text { L-DLPFC } \\
\text { versus Controls }\end{array}$ & $\begin{array}{c}\text { R- DLPFC } \\
\text { versus Controls }\end{array}$ \\
\hline pre & $24.23 \pm 1.92$ & $24.84 \pm 2.6$ & $24.76 \pm 2.61$ & 0.19 & 0.824 & - & - & - \\
\hline post & $23.48 \pm 2$ & $28.85 \pm 2.17$ & $24.46 \pm 3.39$ & 10.82 & $<0.001$ & $p<0.001$ & $p=0.674$ & $p<0.001$ \\
\hline
\end{tabular}

Legend: L-DLPFC: tDCS over Left dorsolateral Prefrontal cortex group; R-DLPFC: tDCS over Right dorsolateral Prefrontal cortex group; p: $p$-value; d.f.: degree of freedom; S.D.: Standard Deviation.

$p=0.42$, Cohen's $d=0.26$ ]. In contrast, when the phonemic fluency session before stimulation and the one after right DLPFC stimulation were compared, a significant increase in performance is recorded $\left[\mathrm{F}_{(1,18)}=26.55, \mathrm{p} \leq 0.001\right.$, Cohen's $\left.d=1.63\right]$. According to Sawilowsky's new effect size rules of thumb, a Cohen's $d$ between 1.2 and 2 indicates a very large effect size [98].

In addition, no learning effect was recorded. When comparing the phonemic fluency performance in the first and the second testing sessions, there were no significant differences in the control group [F $(1,38)=0.119, p=0.73$, Cohen's $d=0.07]$.

\section{DISCUSSION}

These results indicate that C-tDCS over right DLPFC enhances performance in phonemic fluency tasks in mild AD patients and that this effect cannot be accounted for learning effect.

This study investigated the modulating effects of C-tDCS applied to the left and the right DLPFC in a phonemic fluency task in a sample of mild $A D$ patients. The main result is a significant increase in performance after right $\mathrm{C}$-tDCS and no change after left $\mathrm{C}$-tDCS. Indeed, patients receiving right C-DLPFC tDCS improved scores on a verbal fluency task in the post-stimulation session as compared to their pre-stimulation performance. AD patients receiving right DLPFC C-tDCS had significantly higher results when compared to both the patients receiving left DLPFC C-tDCS and to the control subjects who instead received no stimulation.

These findings, together with previous results documenting in healthy subjects a direct involvement of the right PFC in phonemic fluency tasks [16], could suggest that the temporary inhibition of the right DLPFC modulates a linguistic-executive network involving the left hemisphere and facilitating words retrieval while respecting task rules in patients with mild AD. These data are consistent with studies showing a beneficial effect of low-frequency TMS applied to the right inferior frontal gyrus in nonfluent aphasic populations $[38,99,100]$ and would confirm the same effect using C-tDCS. Considering that low-frequency rTMS and C-tDCS are both associated with modulation of inhibitory networks (for a review, see [101]), these results, together with evidence from post-stroke patients, would indicate a close interhemispheric link in the language network $[102,103]$.

Furthermore, we would provide some additional suggestions to the understanding of the neurophysiological mechanisms underpinning the tDCS-induced effects reported in this study.

Neuroimaging findings reported hyperactivations in the right DLPFC in MCI and AD patients and these activations have been frequently interpreted as reflecting compensatory mechanisms [e.g. 104]. However, some studies suggested that hyperactivations in the PFC may represent a dysfunctional use of brain resources in $\mathrm{AD}$, rather than reflecting compensatory mechanisms. In line with this hypothesis, Meinzer and colleagues [105] reported ameliorating effects of brain stimulation in a verbal generation task in MCI patients and suggested a correlation between improved functionality and reductions of hyperactivity of prefrontal regions. This finding suggests that inhibition of right DLPFC may modulate a more general domain involved in the process of retrieving linguistic information. Observation already well documented also in the retrieval of information from the recognition memory [63].

In the present study, inhibitory tDCS over the right DLPFC may modulate the activity in this dysfunctional network, restoring an adaptive equilibrium in $\mathrm{AD}$ patients (see also $[63,75]$ for a discussion of the application of brain stimulation targeting inhibitory networks on cognitive functions).

Another finding that emerged from the present study is that left hemispheric modulation by C-tDCS 
does not significantly affect phonemic fluency performance. This finding would further strengthen that the inhibitory effect that has the greatest impact on fluency tasks is mainly in the right hemisphere. This finding could prompt future research to evaluate whether a similar result will be observed with excitatory brain stimulation protocols in the left hemisphere. This could have an important clinical impact on the modulation of fluency tasks in various patient populations.

Furthermore, this result would show that learning effects do not affect the observed performance increasing after right hemispheric tDCS. In fact, when comparing the performance in the two verbal fluency sessions in the control group, i.e., subjects who had not undergone stimulation, no differences were found. The lack of significant learning effects on VFT performance was indeed reported also in a previous study involving healthy subjects [16].

Recently, several studies in the neurorehabilitative field have investigated the efficacy of tDCS to restore cognitive dysfunctions and behavioral impairments in MCI and AD patients [107]. This study helps to extend the use of non-invasive brain stimulation techniques to $\mathrm{AD}$ patients in the domain of language at the intersection with executive functions, i.e., functions that are impaired since the early stages of dementia [108]. Indeed, it has been adequately supported that the early impairment of executive functions also affects the early stages of dementia $[109,110]$. Improving linguistic productivity using these methods could improve the quality of life and the management of the neurodegenerative course typical of dementia.

Of course, the present study has a sample size limitation that reduces the generalization process of these results. However, they are promising for the study and treatment of cognitive functions related to the neurodegenerative process typical of dementia. Moreover, future research could investigate whether this observed improvement in phonemic fluency can be extended to even more severe stages of $\mathrm{AD}$ and understand up to what level of severity these NIBS tools can be proposed as techniques for treating ADassociated cognitive disorders.

One of the questions that the current study still leaves open is whether this shown effect is maintained on patients of higher severity. The deliberate choice of a sample of patients with a mild level of deterioration is linked to the evidence that tDCS, and more generally neuromodulation techniques, can modulate only to the extent that circuits are still partially spared.
This finding has already been confirmed in memory studies [106]. The observation on patients with mild impairment allows to investigate a language disorder not yet overt. The choice to study language is linked to the search for new methods to impact on cognitive impairment by treating other cognitive domains in addition to memory in patients with mild $\mathrm{AD}$, for example the processes involved in executive functions.

\section{DISCLOSURE STATEMENT}

Authors' disclosures available online (https:// www.j-alz.com/manuscript-disclosures/21-0003r1).

\section{REFERENCES}

[1] Jahanshahi M, Rothwell J (2000) Transcranial magnetic stimulation studies of cognition: An emerging field. Exp Brain Res 131, 1-9.

[2] Pascual-Leone A, Walsh V, Rothwell J (2000) Transcranial magnetic stimulation in cognitive neuroscience-virtual lesion, chronometry, and functional connectivity. Curr Opin Neurobiol 10, 232-237.

[3] Rubens MT, Zanto TP (2012) Parameterization of transcranial magnetic stimulation. J Neurophysiol 107, 1257-1259.

[4] Nitsche MA, Cohen LG, Wassermann EM, Priori A, Lang N, Antal A, Paulus W, Hummel F, Boggio PS, Fregni F (2008) Transcranial direct current stimulation: State of the art 2008. Brain Stimul 1, 206-223.

[5] Fregni F, Pascual-Leone A (2007) Technology insight: Noninvasive brain stimulation in neurology—perspectives on the therapeutic potential of rTMS and tDCS. Nat Clin Pract Neurol 3, 383-393.

[6] Birba A, Ibáñez A, Sedeño L, Ferrari J, García AM, Zimerman M (2017) Non-invasive brain stimulation: A new strategy in mild cognitive impairment? Front Aging $\mathrm{Neu}$ rosci $9,16$.

[7] Prehn K, Flöel A (2015) Potentials and limits to enhance cognitive functions in healthy and pathological aging by tDCS. Front Cell Neurosci 9, 355 .

[8] Klaus J, Schutter DJLG (2018) Non-invasive brain stimulation to investigate language production in healthy speakers: A meta-analysis. Brain Cogn 123, 10-22.

[9] Price AR, McAdams H, Grossman M, Hamilton RH (2015) A meta-analysis of transcranial direct current stimulation studies examining the reliability of effects on language measures. Brain Stimul 8, 1093-1100.

[10] Horvath JC, Forte JD, Carter O (2015) Quantitative review finds no evidence of cognitive effects in healthy populations from single-session transcranial direct current stimulation (tDCS). Brain Stimul 8, 535-550.

[11] Acheson DJ, Hamidi M, Binder JR, Postle BR (2011) A common neural substrate for language production and verbal working memory. J Cogn Neurosci 23, 1358-1367.

[12] Monti A, Ferrucci R, Fumagalli M, Mameli F, Cogiamanian F, Ardolino G, Priori A (2013) Transcranial direct 
current stimulation (tDCS) and language. J Neurol Neurosurg Psychiatry 84, 832-842.

[13] Pobric G, Jefferies E, Ralph MAL (2007) Anterior temporal lobes mediate semantic representation: Mimicking semantic dementia by using rTMS in normal participants. Proc Natl Acad Sci U S A 104, 20137-20141.

[14] Shinshi M, Yanagisawa T, Hirata M, Goto T, Sugata H, Araki T, Okamura Y, Hasegawa Y, Ihara AS, Yorifuji S (2015) Temporospatial identification of language-related cortical function by a combination of transcranial magnetic stimulation and magnetoencephalography. Brain Behav 5, e00317.

[15] Wheat KL, Cornelissen PL, Sack AT, Schuhmann T, Goebel R, Blomert L (2013) Charting the functional relevance of Broca's area for visual word recognition and picture naming in Dutch using fMRI-guided TMS. Brain Lang 125, 223-230.

[16] Smirni D, Turriziani P, Mangano GR, Bracco M, Oliveri M, Cipolotti L (2017) Modulating phonemic fluency performance in healthy subjects with transcranial magnetic stimulation over the left or right lateral frontal cortex. Neuropsychologia 102, 109-115.

[17] Cattaneo Z, Pisoni A, Papagno C (2011) Transcranial direct current stimulation over Broca's region improves phonemic and semantic fluency in healthy individuals. Neuroscience 183, 64-70.

[18] Meinzer M, Antonenko D, Lindenberg R, Hetzer S, Ulm L, Avirame K, Flaisch T, Floel A (2012) Electrical brain stimulation improves cognitive performance by modulating functional connectivity and task-specific activation. $J$ Neurosci 32, 1859-1866.

[19] Penolazzi B, Pastore M, Mondini S (2013) Electrode montage dependent effects of transcranial direct current stimulation on semantic fluency. Behav Brain Res 248, 129-135.

[20] Pisoni A, Mattavelli G, Papagno C, Rosanova M, Casali AG, Romero Lauro LJ (2018) Cognitive enhancement induced by anodal tDCS drives circuit-specific cortical plasticity. Cereb Cortex 28, 1132-1140.

[21] Indefrey P, Levelt WJM (2004) The spatial and temporal signatures of word production components. Cognition $\mathbf{9 2}$, 101-144.

[22] Indefrey P (2011) The spatial and temporal signatures of word production components: A critical update. Front Psychol 2, 255.

[23] Birn RM, Kenworthy L, Case L, Caravella R, Jones TB, Bandettini PA, Martin A (2010) Neural systems supporting lexical search guided by letter and semantic category cues: A self-paced overt response fMRI study of verbal fluency. Neuroimage 49, 1099-1107.

[24] Baldo J V, Schwartz S, Wilkins D, Dronkers NF (2006) Role of frontal versus temporal cortex in verbal fluency as revealed by voxel-based lesion symptom mapping. J Int Neuropsychol Soc 12, 896.

[25] Robinson G, Shallice T, Bozzali M, Cipolotti L (2010) Conceptual proposition selection and the LIFG: Neuropsychological evidence from a focal frontal group. Neuropsychologia 48, 1652-1663.

[26] Henry JD, Crawford JR (2004) Verbal fluency deficits in Parkinson's disease: A meta-analysis. J Int Neuropsychol Soc 10, 608-622.

[27] Koerts J, Meijer HA, Colman KSF, Tucha L, Lange KW, Tucha O (2013) What is measured with verbal fluency tests in Parkinson's disease patients at different stages of the disease? J Neural Transm 120, 403-411.
[28] Shao Z, Janse E, Visser K, Meyer AS (2014) What do verbal fluency tasks measure? Predictors of verbal fluency performance in older adults. Front Psychol 5, 772.

[29] Vonberg I, Ehlen F, Fromm O, Klostermann F (2014) The absoluteness of semantic processing: Lessons from the analysis of temporal clusters in phonemic verbal fluency. PLoS One 9, e115846.

[30] Whiteside DM, Kealey T, Semla M, Luu H, Rice L, Basso MR, Roper B (2016) Verbal fluency: Language or executive function measure? Appl Neuropsychol Adult 23, 29-34.

[31] Stuss DT, Alexander MP, Hamer L, Palumbo C, Dempster R, Binns M, Levine B, Izukawa D (1998) The effects of focal anterior and posterior brain lesions on verbal fluency. J Int Neuropsychol Soc 4, 265-278.

[32] Lezak MD, Howieson DB, Loring DW, Fischer JS (2004) Neuropsychological assessment, Oxford University Press, USA.

[33] Robinson G, Shallice T, Bozzali M, Cipolotti L (2012) The differing roles of the frontal cortex in fluency tests. Brain 135, 2202-2214.

[34] Milner B (1964) Some effects of frontal lobectomy in man. In The Frontal Granular Cortex and Behavior, pp. 313334.

[35] CipolottiL, Molenberghs P, Dominguez J, Smith N, Smirni D, Xu T, Shallice T, Chan E (2020) Fluency and rule breaking behaviour in the frontal cortex. Neuropsychologia 137, 107308.

[36] Lumley MA, Neely LC, Burger AJ (2007) The assessment of alexithymia in medical settings: Implications for understanding and treating health problems. J Pers Assess 89, 230-246.

[37] Raoux N, Amieva H, Le Goff M, Auriacombe S, Carcaillon L, Letenneur L, Dartigues J-F (2008) Clustering and switching processes in semantic verbal fluency in the course of Alzheimer's disease subjects: Results from the PAQUID longitudinal study. Cortex $\mathbf{4 4}$, 1188-1196.

[38] Fisicaro F, Lanza G, Grasso AA, Pennisi G, Bella R, Paulus W, Pennisi M (2019) Repetitive transcranial magnetic stimulation in stroke rehabilitation: Review of the current evidence and pitfalls. Ther Adv Neurol Disord 12, 1756286419878317.

[39] Lefaucheur J-P (2006) Stroke recovery can be enhanced by using repetitive transcranial magnetic stimulation (rTMS). Neurophysiol Clin Neurophysiol 36, 105-115.

[40] Maeda F, Keenan JP, Tormos JM, Topka H, Pascual-Leone A (2000) Modulation of corticospinal excitability by repetitive transcranial magnetic stimulation. Clin Neurophysiol 111, 800-805.

[41] Pascual-Leone A, Tormos JM, Keenan J, Tarazona F, Cañete C, Catalá MD (1998) Study and modulation of human cortical excitability with transcranial magnetic stimulation. J Clin Neurophysiol 15, 333-343.

[42] Martin PI, Naeser MA, Ho M, Doron KW, Kurland J, Kaplan J, Wang Y, Nicholas M, Baker EH, Fregni F (2007) Overt naming fMRI pre-and post-TMS: Two nonfluent aphasia patients, with and without improved naming postTMS. Brain Lang 103, 248-249.

[43] Martin PI, Naeser MA, Ho M, Treglia E, Kaplan E, Baker EH, Pascual-Leone A (2009) Research with transcranial magnetic stimulation in the treatment of aphasia. Curr Neurol Neurosci Rep 9, 451.

[44] Rossetti A, Malfitano C, Malloggi C, Banco E, Rota V, Tesio L (2019) Phonemic fluency improved after 
inhibitory transcranial magnetic stimulation in a case of chronic aphasia. Int J Rehabil Res 42, 92.

[45] Naeser MA, Martin PI, Nicholas M, Baker EH, Seekins H, Helm-Estabrooks N, Cayer-Meade C, Kobayashi M, Theoret H, Fregni F, Tormos JM, Kurland J, Doron KW, Pascual-Leone A (2005) Improved naming after TMS treatments in a chronic, global aphasia patient-case report. Neurocase 11, 182-193.

[46] Higgins ES, George MS (2019) Brain stimulation therapies for clinicians, American Psychiatric Pub.

[47] Baker JM, Rorden C, Fridriksson J (2010) Using transcranial direct-current stimulation to treat stroke patients with aphasia. Stroke 41, 1229-1236.

[48] Fertonani A, Rosini S, Cotelli M, Rossini PM, Miniussi C (2010) Naming facilitation induced by transcranial direct current stimulation. Behav Brain Res 208, 311-318.

[49] Marangolo P, Fiori V, Di Paola M, Cipollari S, Razzano C, Oliveri M, Caltagirone C (2013) Differential involvement of the left frontal and temporal regions in verb naming: A tDCS treatment study. Restor Neurol Neurosci 31, 63-72.

[50] Fridriksson J, Richardson JD, Baker JM, Rorden C (2011) Transcranial direct current stimulation improves naming reaction time in fluent aphasia: A double-blind, shamcontrolled study. Stroke 42, 819-821.

[51] Fiori V, Coccia M, Marinelli C V, Vecchi V, Bonifazi S, Ceravolo MG, Provinciali L, Tomaiuolo F, Marangolo P (2011) Transcranial direct current stimulation improves word retrieval in healthy and nonfluent aphasic subjects. $J$ Cogn Neurosci 23, 2309-2323.

[52] Flöel A, Rösser N, Michka O, Knecht S, Breitenstein C (2008) Noninvasive brain stimulation improves language learning. J Cogn Neurosci 20, 1415-1422.

[53] Kang EK, Kim YK, Sohn HM, Cohen LG, Paik N-J (2011) Improved picture naming in aphasia patients treated with cathodal tDCS to inhibit the right Broca's homologue area. Restor Neurol Neurosci 29, 141-152.

[54] Henry JD, Crawford JR, Phillips LH (2004) Verbal fluency performance in dementia of the Alzheimer's type: A metaanalysis. Neuropsychologia 42, 1212-1222.

[55] Taler V, Phillips NA (2008) Language performance in Alzheimer's disease and mild cognitive impairment: A comparative review. J Clin Exp Neuropsychol 30, 501-556.

[56] Swanberg MM, Tractenberg RE, Mohs R, Thal LJ, Cummings JL (2004) Executive dysfunction in Alzheimer disease. Arch Neurol 61, 556-560.

[57] Canning SJD, Leach L, Stuss D, Ngo L, Black SE (2004) Diagnostic utility of abbreviated fluency measures in Alzheimer disease and vascular dementia. Neurology 62, 556-562.

[58] Caramelli P, Carthery-Goulart MT, Porto CS, CharchatFichman H, Nitrini R (2007) Category fluency as a screening test for Alzheimer disease in illiterate and literate patients. Alzheimer Dis Assoc Disord 21, 65-67.

[59] Cerhan JH, Ivnik RJ, Smith GE, Tangalos EC, Petersen RC, Boeve BF (2002) Diagnostic utility of letter fluency, category fluency, and fluency difference scores in Alzheimer's disease. Clin Neuropsychol 16, 35-42.

[60] Monsch AU, Bondi MW, Butters N, Salmon DP, Katzman R, Thal LJ (1992) Comparisons of verbal fluency tasks in the detection of dementia of the Alzheimer type. Arch Neurol 49, 1253-1258.

[61] Clark LJ, Gatz M, Zheng L, Chen Y-L, McCleary C, Mack WJ (2009) Longitudinal verbal fluency in normal aging, preclinical, and prevalent Alzheimer's disease. Am J Alzheimers Dis Other Dementias 24, 461-468.
[62] Alegret M, Peretó M, Pérez A, Valero S, Espinosa A, Ortega G, Hernández I, Mauleón A, Rosende-Roca M, Vargas L (2018) The role of verb fluency in the detection of early cognitive impairment in Alzheimer's disease. $J$ Alzheimers Dis 62, 611-619.

[63] Turriziani P, Smirni D, Zappalá G, Mangano GR, Oliveri M, Cipolotti L (2012) Enhancing memory performance with rTMS in healthy subjects and individuals with mild cognitive impairment: The role of the right dorsolateral prefrontal cortex. Front Hum Neurosci 6, 62.

[64] Boggio PS, Khoury LP, Martins DCS, Martins OEMS, De Macedo EC, Fregni F (2009) Temporal cortex direct current stimulation enhances performance on a visual recognition memory task in Alzheimer disease. J Neurol Neurosurg Psychiatry 80, 444-447.

[65] Ferrucci R, Mameli F, Guidi I, Mrakic-Sposta S, Vergari M, Marceglia S, Cogiamanian F, Barbieri S, Scarpini E, Priori A (2008) Transcranial direct current stimulation improves recognition memory in Alzheimer disease. Neurology 71, 493-498.

[66] Boggio PS, Ferrucci R, Mameli F, Martins D, Martins O, Vergari M, Tadini L, Scarpini E, Fregni F, Priori A (2012) Prolonged visual memory enhancement after direct current stimulation in Alzheimer's disease. Brain Stimul 5, 223-230.

[67] Koch G, Bonní S, Pellicciari MC, Casula EP, Mancini M, Esposito R, Ponzo V, Picazio S, Di Lorenzo F, Serra L (2018) Transcranial magnetic stimulation of the precuneus enhances memory and neural activity in prodromal Alzheimer's disease. Neuroimage 169, 302-311.

[68] Bystad M, Grønli O, Rasmussen ID, Gundersen N, Nordvang L, Wang-Iversen H, Aslaksen PM (2016) Transcranial direct current stimulation as a memory enhancer in patients with Alzheimer's disease: A randomized, placebo-controlled trial. Alzheimers Res Ther $\mathbf{8}, 13$.

[69] Murugaraja V, Shivakumar V, Sivakumar PT, Sinha P, Venkatasubramanian G (2017) Clinical utility and tolerability of transcranial direct current stimulation in mild cognitive impairment. Asian J Psychiatr 30, 135-140.

[70] Manenti R, Sandrini M, Gobbi E, Binetti G, Cotelli M (2020) Effects of transcranial direct current stimulation on episodic memory in amnestic mild cognitive impairment: A pilot study. J Gerontol B Psychol Sci Soc Sci 75, 14031413.

[71] Bystad M, Rasmussen ID, Grønli O, Aslaksen PM (2017) Can 8 months of daily tDCS application slow the cognitive decline in Alzheimer's disease? A case study. Neurocase 23, 146-148.

[72] Cotelli M, Calabria M, Manenti R, Rosini S, Zanetti O, Cappa SF, Miniussi C (2011) Improved language performance in Alzheimer disease following brain stimulation. J Neurol Neurosurg Psychiatry 82, 794-797.

[73] Cotelli M, Manenti R, Cappa SF, Zanetti O, Miniussi C (2008) Transcranial magnetic stimulation improves naming in Alzheimer disease patients at different stages of cognitive decline. Eur J Neurol 15, 1286-1292.

[74] Costa V, Brighina F, Piccoli T, Realmuto S, Fierro B (2017) Anodal transcranial direct current stimulation over the right hemisphere improves auditory comprehension in a case of dementia. Neurorehabilitation 41, 567-575.

[75] Turriziani P, Smirni D, Mangano GR, Zappalá G, Giustiniani A, Cipolotti L, Oliveri M (2019) Low-frequency repetitive transcranial magnetic stimulation of the right dorsolateral prefrontal cortex enhances recognition memory in Alzheimer's disease. J Alzheimers Dis 72, 613-622. 
[76] McKhann GM, Knopman DS, Chertkow H, Hyman BT, Jack Jr CR, Kawas CH, Klunk WE, Koroshetz WJ, Manly JJ, Mayeux R (2011) The diagnosis of dementia due to Alzheimer's disease: Recommendations from the National Institute on Aging-Alzheimer's Association workgroups on diagnostic guidelines for Alzheimer's disease. Alzheimers Dement 7, 263-269.

[77] Folstein MF, Folstein SE, McHugh PR (1975) "Minimental state": A practical method for grading the cognitive state of patients for the clinician. J Psychiatr Res 12, 189198.

[78] Raven JC (1995) Coloured Progressive Matrices Sets A, $\mathrm{Ab}, \mathrm{B}$. Manual Sections $1 \& 2$.

[79] Smirni D (2020) The Raven's Coloured Progressive Matrices in healthy children: A qualitative approach. Brain Sci 10, 877.

[80] Monaco M, Costa A, Caltagirone C, Carlesimo GA (2013) Forward and backward span for verbal and visuo-spatial data: Standardization and normative data from an Italian adult population. Neurol Sci 34, 749-754.

[81] Smirni D, Smirni P, Di Martino G, Cipolotti L, Oliveri M, Turriziani P (2018) Standardization and validation of a parallel form of the verbal and non-verbal recognition memory test in an Italian population sample. Neurol Sci 39, 1391-1399.

[82] Smirni D, Smirni P, Di Martino G, Fontana ML, Cipolotti L, Oliveri M, Turriziani P (2019) Early detection of memory impairments in older adults: Standardization of a short version of the verbal and nonverbal Recognition Memory Test. Neurol Sci 40, 97-103.

[83] Caltagirone C, Gainotti G, Carlesimo GA, Parnetti L (1995) Batteria per la valutazione del deterioramento mentale: I. Descrizione di uno strumento di diagnosi neuropsicologica. Arch Psicol Neurol Psichiatr 56, 461-470.

[84] Rey A (1964) L'examen clinique en psychologie [The clinical psychological examination]. Presses universitaires de France, Paris.

[85] Miceli G, Laudanna A, Burani C, Capasso R (1994) Batteria per l'analisi dei deficit afasici. B.A.D.A., Roma, Italy.

[86] Caffarra P, Vezzadini G, Dieci F, Zonato F, Venneri A (2002) Una versione abbreviata del test di Stroop: Dati normativi nella popolazione italiana. Nuova Riv Neurol 12, 111-115.

[87] Carlesimo GA, Caltagirone C, Gainotti G, Fadda L, Gallassi R, Lorusso S, Marfia G, Marra C, Nocentini U, Parnetti L (1996) The mental deterioration battery: Normative data, diagnostic reliability and qualitative analyses of cognitive impairment. Eur Neurol 36, 378-384.

[88] Snaith RP (2003) The hospital anxiety and depression scale. Health Qual Life Outcomes 1, 1-4.

[89] Katz S (1983) Assessing self-maintenance: Activities of daily living, mobility, and instrumental activities of daily living. J Am Geriatr Soc 31, 721-727.

[90] Lawton MP, Brody EM (1969) Assessment of older people: Self-maintaining and instrumental activities of daily living. Gerontologist 9, 179-186.

[91] Smirni D, Turriziani P, Mangano GR, Cipolotti L, Oliveri M (2015) Modulating memory performance in healthy subjects with transcranial direct current stimulation over the right dorsolateral prefrontal cortex. PLoS One 10, e0144838.

[92] Costanzo F, Varuzza C, Rossi S, Sdoia S, Varvara P, Oliveri M, Giacomo K, Vicari S, Menghini D (2016) Evidence for reading improvement following tDCS treatment in children and adolescents with dyslexia. Restor Neurol Neurosci 34, 215-226.

[93] Poreisz C, Boros K, Antal A, Paulus W (2007) Safety aspects of transcranial direct current stimulation concerning healthy subjects and patients. Brain Res Bull 72, 208-214.

[94] Nitsche MA, Schauenburg A, Lang N, Liebetanz D, Exner C, Paulus W, Tergau F (2003) Facilitation of implicit motor learning by weak transcranial direct current stimulation of the primary motor cortex in the human. J Cogn Neurosci 15, 619-626.

[95] Miniussi C, Cappa SF, Cohen LG, Floel A, Fregni F, Nitsche MA, Oliveri M, Pascual-Leone A, Paulus W, Priori A (2008) Efficacy of repetitive transcranial magnetic stimulation/transcranial direct current stimulation in cognitive neurorehabilitation. Brain Stimul 1, 326-336.

[96] Carlesimo GA, Caltagirone C, Fadda LM, Marfia GA, Gainotti G, Gallassi R, Lorusso S, Marra C, Nocentini U, Parnetti L (1995) Batteria per la valutazione del Deterioramento Mentale (parte III): Analisi dei profili qualitativi di compromissione cognitiva. Arch Psicol Neurol Psichiatr 56, 489-489.

[97] Novelli G, Papagno C, Capitani E, Laiacona M (1986) Tre test clinici di ricerca e produzione lessicale. Taratura su sogetti normali. Arch Psicol Neurol Psichiatr 47, 477-506.

[98] Sawilowsky SS (2009) New effect size rules of thumb. $J$ Mod Appl Stat Methods 8, 26.

[99] Weiduschat N, Thiel A, Rubi-Fessen I, Hartmann A, Kessler J, Merl P, Kracht L, Rommel T, Heiss WD (2011) Effects of repetitive transcranial magnetic stimulation in aphasic stroke: A randomized controlled pilot study. Stroke 42, 409-415.

[100] Naeser MA, Martin PI, Treglia E, Ho M, Kaplan E, Bashir S, Hamilton R, Coslett HB, Pascual-Leone A (2010) Research with rTMS in the treatment of aphasia. Restor Neurol Neurosci 28, 511-529.

[101] Valero-Cabré A, Toba MN, Hilgetag CC, Rushmore RJ (2020) Perturbation-driven paradoxical facilitation of visuo-spatial function: Revisiting the 'Sprague effect.' Cortex 122, 10-39.

[102] Kim YH, Ko MH, Parrish TB, Kim HG (2002) Reorganization of cortical language areas in patients with aphasia: A functional MRI study. Yonsei Med J 43, 441-445.

[103] Thulborn KR, Carpenter PA, Just MA (1999) Plasticity of language-related brain function during recovery from stroke. Stroke 30, 749-754.

[104] Grady CL, McIntosh AR, Beig S, Keightley ML, Burian H, Black SE (2003) Evidence from functional neuroimaging of a compensatory prefrontal network in Alzheimer's disease. J Neurosci 23, 986-993.

[105] Meinzer M, Lindenberg R, Phan MT, Ulm L, Volk C, Flöel A (2015) Transcranial direct current stimulation in mild cognitive impairment: Behavioral effects and neural mechanisms. Alzheimers Dement 11, 1032-1040.

[106] Turriziani P, Smirni D, Mangano GR, Zappalá G, Giustiniani A, Cipolotti L, Oliveri M (2019) Lowfrequency repetitive transcranial magnetic stimulation of the right dorsolateral prefrontal cortex enhances recognition memory in Alzheimer's disease. J Alzheimers Dis 72, 613-622.

[107] Pellicciari MC, Miniussi C (2018) Transcranial direct current stimulation in neurodegenerative disorders. JECT 34, 193-202.

[108] Guarino A, Favieri F, Boncompagni I, Agostini F, Cantone M, Casagrande M (2019) Executive functions in 
Alzheimer disease: A systematic review. Front Aging Neurosci 10, 437.

[109] Amieva H, Lafont S, Rouch-Leroyer I, Rainville C, Dartigues J-F, Orgogozo J-M, Fabrigoule C (2004) Evidencing inhibitory deficits in Alzheimer's disease through interference effects and shifting disabilities in the Stroop test. Arch Clin Neuropsychol 19, 791-803.
[110] Bondi MW, Serody AB, Chan AS, Eberson-Shumate SC, Delis DC, Hansen LA, Salmon DP (2002) Cognitive and neuropathologic correlates of Stroop Color-Word Test performance in Alzheimer's disease. Neuropsychology 16, 335 . 